\title{
BMJ Open Under-5 mortality in sub-Saharan Africa: is maternal age at first childbirth below 20 years a risk factor?
}

\author{
Bright Opoku Ahinkorah (D)
}

To cite: Ahinkorah B0. Under-5 mortality in sub-Saharan Africa: is maternal age at first childbirth below 20 years a risk factor? BMJ Open 2021;11:e049337. doi:10.1136/ bmjopen-2021-049337

- Prepublication history and additional supplemental material for this paper are available online. To view these files, please visit the journal online (http://dx.doi.org/10.1136/ bmjopen-2021-049337)

Received 26 January 2021 Accepted 06 September 2021

Check for updates

(C) Author(s) (or their employer(s)) 2021. Re-use permitted under CC BY-NC. No commercial re-use. See rights and permissions. Published by BMJ.

School of Public Health, University of Technology Sydney, Sydney, New South Wales, Australia

Correspondence to Bright Opoku Ahinkorah; brightahinkorah@gmail.com

\section{ABSTRACT}

Objectives This study aimed at examining the association between young maternal age at first childbirth and under-5 mortality in sub-Saharan Africa (SSA).

Design and setting This cross-sectional study pooled nationally-representative data from the most recent Demographic and Health Surveys conducted in 30 countries in SSA from 2010 to 2019.

Participants 116379 mothers of children under 5 . Results The prevalence of adolescent childbirth and death in children under 5 in SSA were $57.36 \%$ (95\% Cl $53.73 \%$ to $60.99 \%)$ and $4.10 \%(95 \% \mathrm{Cl} 3.65 \%$ to $4.54 \%$ ), respectively. Children born to mothers whose first childbirth occurred at $<20$ years were $11 \%$ more likely to die before the age of 5 compared with those whose mothers' first childbirth occurred at age $\geq 20$ years (adjusted odds ratio (aOR) 1.11; 95\% Cl 1.05 to 1.18). In terms of the covariates, the likelihood of under-5 mortality was higher among children born to single (aOR 1.54; 95\% Cl 1.41 to 1.67) and cohabiting mothers (aOR 1.10; 95\% $\mathrm{Cl} 1.01$ to 1.21) compared with married mothers. Children born to mothers who were obese were more likely to die before the age of 5 compared with those born to mothers with normal body weight (aOR $1.17 ; 95 \% \mathrm{Cl} 1.09$ to 1.26). The odds of under- 5 mortality were higher among children whose weight at birth was <2500 g compared with those whose weight was $\geq 2500 \mathrm{~g}$ at birth (aOR $1.83 ; 95 \% \mathrm{Cl}$ 1.64 to 2.03).

Conclusions The findings call for the need to enhance policies aimed at reducing under- 5 mortality in SSA by reducing adolescent pregnancy and childbirth through family planning, comprehensive sexuality education, and the elimination of child marriage. Again, Since under-5 mortality among adolescent mothers is linked with their poor socio-economic status, there is the need for government and non-governmental organisations in SSA to introduce poverty alleviation programmes and improve access to both formal and informal education as a way of enhancing the socioeconomic status of adolescent mothers. Public health education, through continuous advocacy programmes should be done to encourage adolescent mothers to access antenatal care and health facility deliveries as a way of enhancing the survival status of their children. These interventions should be implemented, taking into consideration other characteristics of mothers such marital status and BMI and child's characteristics such as child's weight, which were found to be associated with high under- 5 mortality.

\section{STRENGTHS AND LIMITATIONS OF THIS STUDY}

$\Rightarrow$ The use of large nationally representative datasets of 30 countries in sub-Saharan Africa is a major strength of this study.

$\Rightarrow$ Again, the large sample size made it possible to use high level statistical analyses that confirm the accuracy of the findings.

$\Rightarrow$ In terms of limitations, the design employed in the Demographic and Health Surveys is cross-sectional and hence, causal interpretations of the findings cannot be established.

$\Rightarrow$ Age at first childbirth was self-reported, and as a result, there is the possibility of under-reporting and over-reporting of data.

\section{INTRODUCTION}

Death of children under 5 is a significant health indicator and a key development index for nations worldwide. ${ }^{1}$ Between 1990 and 2018, the global under-5 mortality rate reduced by $52 \%$ from 93 deaths per 1000 live births to 39 deaths per 1000 live births. ${ }^{2}$ This decline has not been experienced in all regions as the chances of a child's survival from birth to 59 months have differed from one region to another. ${ }^{3-5}$ Globally, subSaharan Africa (SSA) has been considered as the region with the highest under-5 mortality rate. ${ }^{6-9}$ For instance, in 2018, SSA recorded an under-5 mortality rate of 78 deaths per 1000 live births, compared with 39 deaths per 1000 live births globally and this translated to 1 death for every 13 live births, compared with 1 death for every 199 live births in highincome countries. ${ }^{2}$

The Sustainable Development Goal-3 aims to reduce under- 5 mortality rate to at least 25 per 1000 live births by $2030 .{ }^{10}$ In line with this, $\mathrm{WHO}^{11}$ has recommended strategies such as access to nutrition and micronutrients, exclusive breastfeeding, skilled antenatal care (ANC) and birth attendance, and postnatal care as means of improving the health status of children and enhancing their chances of survival. However, evidence has shown that 
most of these strategies are beyond the reach of a number of sub-Saharan African countries, due to the absence of empirical data on the causes of under-5 mortality in most of the countries in SSA. ${ }^{12-15}$

In SSA, the major causes of under-5 deaths include pregnancy-related complications, pneumonia, diarrhoea, neonatal sepsis and malaria. ${ }^{16}$ Apart from these causes, studies have found several maternal and child factors such as maternal age, place of residence, level of education, wealth quintile, sex of the child, birth rank, size of the child at birth, place of delivery, assistance during delivery, and number of ANC attendance as factors associated with deaths of children under 5 in SSA. ${ }^{6791718}$

Other studies have shown that maternal age at first birth is associated with adverse birth outcomes such as neonatal mortality, ${ }^{19}$ low birth weight, pre-eclampsia/eclampsia, preterm birth, and maternal and perinatal mortality in SSA. ${ }^{20}$ This has been found to occur because women who give birth at young age are more likely to be less wealthy and have received less education ${ }^{21} 22$ and may make less use of maternal and child healthcare services. ${ }^{2324}$ Moreover, since such births are more likely to be their first birth, they carry increased risks. ${ }^{25}$

Globally, several studies have found that children born to mothers whose first childbirth occurred during adolescence are more likely to die before age 5 compared with those born to mothers whose first childbirth occurred in adulthood ${ }^{26-29}$ In SSA, there are studies that have shown that adolescent pregnancy and childbirth do not only have short-term and medium-term negative effects on the adolescent girl but established long-term effects as well. ${ }^{30}{ }^{31}$ These studies explained that most adolescents in SSA who have experienced adolescent pregnancy or childbirth are likely to be socioeconomically disadvantaged even after several years due to school drop-outs, unemployment, and abandonment by parents. ${ }^{31} 32$ Others may also experience long-term psychological problems such as anxiety and depression due to stigmatisation. ${ }^{33-35}$ These negative situations may affect the health status of their subsequent children who are even born when they are adults.

Considering that SSA has the highest prevalence of under-5 mortality ${ }^{6-9}$ and adolescent childbearing globally, ${ }^{36} 37$ understanding the association between young maternal age at first childbirth and under-5 mortality in SSA is critical for policy and public health interventions. However, the only available evidence on the association between young maternal age at first childbirth and under-5 mortality in SSA have been done only in specific countries such as Nigeria ${ }^{38}$ and South Sudan. ${ }^{39}$ To the best of the author's knowledge, there has not been any study that has used pooled data accross a number of countries in SSA to examine the association between young maternal age at first childbirth and under-5 mortality. Again, considering the long-term effects of adolescent childbearing in SSA, it is important to understand its negative health effect not only for the firstborn children of adolescent mothers but their subsequent children as well, including those who were born when they were adults. The current study seeks to fill the gap in dearth of evidence by examining the association between young maternal age at first birth and under-5 mortality in SSA using data from the Demographic and Health Surveys (DHS) of 30 countries.

In this study, it is hypothesised that children of mothers whose first childbirth occurred when they were adolescents (less than 20 years) are more likely to die before the age of 5 compared with those whose mothers' first childbirth occurred at age 20 years and above. Findings from the study will be useful to government and nongovernmental organisations of these countries in implementing and strengthening existing childhood healthcare programmes that can help improve child survival and reduce the high under-5 mortality rate in SSA.

\section{METHODS}

\section{Study design}

The birth recode files of the DHS of 30 countries in SSA, which contain data on the full birth history of all women interviewed and information on health indicators as well as fertility and mortality rates were used. Data for the DHS are mostly gathered every 5 years. However, this period can be longer in some countries due to specific country conditions. Data for each survey are obtained by sampling respondents using a two-stage sampling technique. The two stage sampling process begins with the selection of clusters usually called enumeration areas. This is followed by the selection of households for the survey. Details on the sampling methodology and data collection used by the DHS are published elsewhere. ${ }^{40}$ In this study, the inclusion criteria were countries whose datasets were published between 2010 and 2019 and had information on age at first birth, child mortality and all other variables that were considered essential in this study. In all, 116379 mothers of children under 5 were included in this study. The countries included in this study and their samples are shown in table 1 . The manuscript was prepared in line with the Strengthening Reporting of Observational studies in Epidemiology reporting guidelines ${ }^{41}$ as found in online supplemental table S1.

\section{Study variables}

\section{Outcome variable}

The outcome variable for this study was under-5 mortality, which has been defined as the death of children under-5 years. ${ }^{142}$ This variable was recoded as a binary variable $(0=$ no and $1=$ yes $) \cdot{ }^{917}$

\section{Key explanatory variable}

The main explanatory variable of the study was 'age at first childbirth'. This variable was derived from the question, 'how old were you when you first gave birth?' The responses to this question were in single years. For the purpose of this study, respondents who mentioned $<20$ years as their ages at the time of their first childbirth were considered as those who had 'adolescent 


\begin{tabular}{|c|c|c|c|}
\hline $\begin{array}{l}\text { Survey } \\
\text { countries }\end{array}$ & $\begin{array}{l}\text { Survey } \\
\text { year }\end{array}$ & $\begin{array}{l}\text { Weighted } \\
\text { sample }\end{array}$ & Percentage \\
\hline Benin & 2018 & 4584 & 3.94 \\
\hline Burkina Faso & 2010 & 5339 & 4.59 \\
\hline Burundi & 2017 & 4299 & 3.69 \\
\hline Cameroon & 2018 & 3503 & 3.01 \\
\hline Chad & 2015 & 7201 & 6.19 \\
\hline Comoros & 2012 & 2056 & 1.77 \\
\hline Congo & 2011-2012 & 3142 & 2.70 \\
\hline Congo DR & 2013-2014 & 5557 & 4.77 \\
\hline Cote D'Ivoire & 2011-2012 & 2538 & 2.18 \\
\hline Ethiopia & 2016 & 7330 & 6.30 \\
\hline Gabon & 2012 & 2518 & 2.16 \\
\hline Gambia & 2013 & 2530 & 2.17 \\
\hline Ghana & 2014 & 2128 & 1.83 \\
\hline Guinea & 2018 & 2799 & 2.40 \\
\hline Kenya & 2014 & 6767 & 5.81 \\
\hline Lesotho & 2014 & 1329 & 1.14 \\
\hline Liberia & 2013 & 2490 & 2.14 \\
\hline Malawi & 2016 & 4478 & 3.85 \\
\hline Mali & 2018 & 3262 & 2.80 \\
\hline Namibia & 2013 & 1813 & 1.56 \\
\hline Niger & 2012 & 3848 & 3.31 \\
\hline Nigeria & 2018 & 8418 & 7.23 \\
\hline Rwanda & 2015 & 2952 & 2.54 \\
\hline Senegal & 2010-2011 & 3044 & 2.62 \\
\hline Sierra Leone & 2019 & 3675 & 3.16 \\
\hline South Africa & 2016 & 1226 & 1.05 \\
\hline Tanzania & 2016 & 6965 & 5.98 \\
\hline Togo & 2013-2014 & 2473 & 2.13 \\
\hline Uganda & 2016 & 3339 & 2.87 \\
\hline Zimbabwe & 2015 & 4776 & 4.10 \\
\hline All countries & & 116379 & 100.00 \\
\hline
\end{tabular}

childbirth' while those whose first childbirth occurred at $\geq 20$ years were considered as those who gave birth as adults (adult childbirth).

\section{Covariates}

Based on the findings of previous studies on factors associated with under-5 mortality, ${ }^{9} 174243$ eleven variables, made up of nine individual-level factors (marital status, pregnancy intention, mother's education level, mother's body mass index (BMI), sex of child, child's weight, number of ANC visits, place of delivery, and assistant during delivery) and two contextual factors (wealth quintile and place of residence) were considered as the main covariates. Marital status was coded as married, cohabiting and single (never married, widowed, divorced, and separated). Pregnancy intention was coded as intended, mistimed and unwanted while mother's educational level was coded as no education, primary, and secondary/higher. Mother's BMI was coded as thin $(<18.5 \mathrm{~kg} / \mathrm{m} 2)$, normal $(18.5-$ $24.9 \mathrm{~kg} / \mathrm{m} 2)$, and obese $(>25 \mathrm{~kg} / \mathrm{m} 2)$. Sex of the child was coded as male and female and child's birth weight was coded as $\geq 2500 \mathrm{~g}$ and $<2500 \mathrm{~g}$. The number of ANC visits was coded as less than four visits and four or more visits. Place of delivery was coded as home and health facility while assistant during delivery was coded as Traditional Birth Attendant (TBA)/others and Skilled Birth Attendant (SBA)/health professional. Wealth index was coded as poorest, poorer, middle, richer, and richest. Place of residence was coded as urban and rural. Apart from these, subregions (Central, West, East and Southern Africa) and survey years were also considered as additional covariates. The countries were categorised into subregions based on their specific location within Africa as defined by the United Nations. ${ }^{44}$ These are West Africa (Burkina Faso, Benin, Cote D'lvoire, Ghana, Gambia, Guinea, Liberia, Mali, Nigeria, Niger, Sierra Leone, Senegal, and Togo), East Africa (Burundi, Ethiopia, Kenya, Comoros, Malawi, Rwanda, Tanzania, and Uganda), Central Africa (Congo DR, Congo, Cameroon, Gabon, and Chad) and South Africa (Lesotho, Namibia, South Africa, and Zimbabwe).

\section{Statistical analysis}

Data analyses were carried out using Stata V.14.0. First, the prevalence of adolescent childbirth and under-5 mortality were presented using forest plots, with their associated $95 \%$ confidencen intervals (CI) and weights. Next, the weighted frequencies and percentages for the covariates and their distribution across age at first childbirth and under-5 death were presented, followed by a $\chi^{2}$ test of independence. Finally, multilevel logistic regression models were used to show the association between age at first childbirth and under-5 mortality while controlling for the covariates. Model 0 showed the variance in under- 5 mortality attributed to the clustering of the primary sampling units without the explanatory variables. Model I and model II contained the key explanatory variable (age at first childbirth) and the individuallevel factors, respectively. The final model (model III) had the key explanatory variable and all the covariates. The Stata command 'melogit' was used in fitting these models. The Akaike's information criterion (AIC) tests were used for model comparison. The results were presented as crude odds ratios (cORs) and adjusted odds ratios (aORs), at 95\% CIs. Sampling weights were applied to cater for under-sampling and over-sampling. ${ }^{45}$ Finally, the survey command in Stata was used to adjust for the complex sampling structure of the data in the regression analyses. 


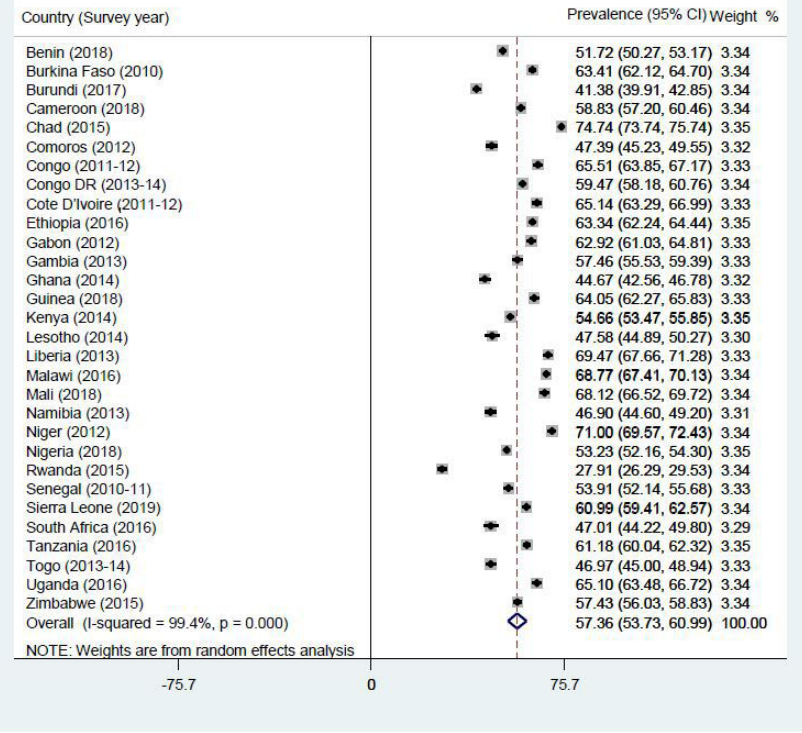

Figure 1 Forest plot showing prevalence of adolescent childbirth in sub-Saharan Africa by country.

\section{Patient and public involvement}

Patients and the public were not involved in the design and conduct of this research.

\section{RESULTS}

\section{Prevalence of adolescent childbirth in SSA}

In the 30 countries in SSA, the prevalence of adolescent childbirth was $57.36 \%$ (95\% CI 53.73\% to 60.99 ), ranging from as high as $74.74 \%$ (95\% CI $73.74 \%$ to $75.74 \%$ ) in Chad to as low as $27.91 \%$ in Rwanda (95\% CI $26.29 \%$ $29.53 \%$ ) (figure 1).

\section{Prevalence of under-5 mortality in SSA}

The prevalence of death among children under 5 in the 30 countries in SSA was $4.10 \%$ (95\% CI $3.65 \%$ to $4.54 \%$ ). The highest prevalence of $6.95 \%$ (95\% CI $6.13 \%$ to $7.77 \%$ ) was in Sierra Leone while the lowest prevalence of $2.25 \%$ (95\% CI $1.67 \%$ to $2.83 \%$ ) was in Gambia (figure 2).

\section{Distribution of sociodemographic characteristics across age at first childbirth and death of children under 5}

Table 2 shows results of the distribution of the sociodemographic characteristics of mothers across adolescent mothers versus older mothers and under- 5 deaths versus no deaths. The results showed statistically significant difference between all the sociodemographic characteristics and age at first childbirth, except sex of the child. Statistically significant difference was also observed between the sociodemographic characteristics of mothers and under-5 mortality, except mother's BMI.

In terms of adolescent childbirth, the prevalence was higher among cohabiting mothers $(60.62 \%)$, compared

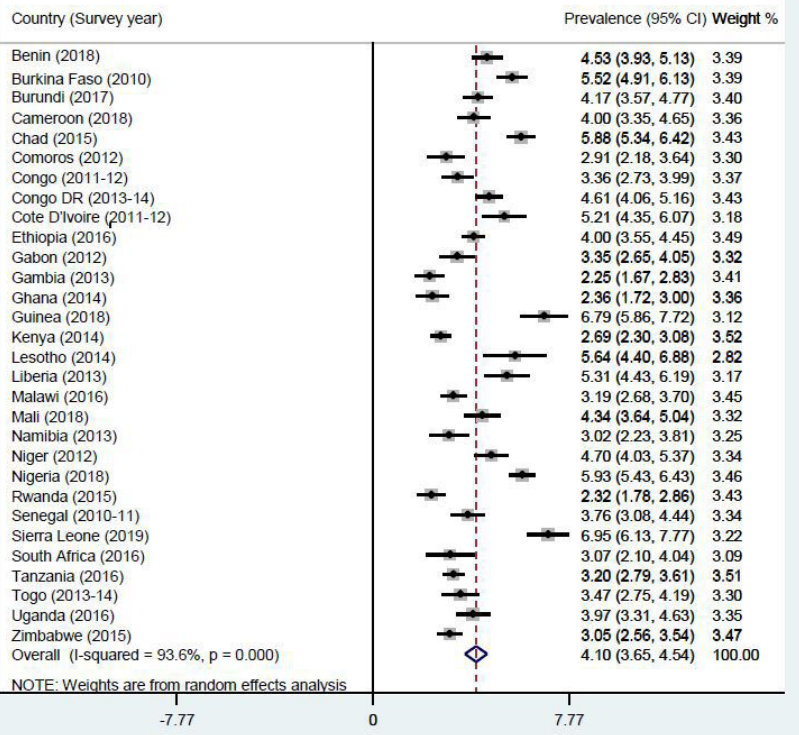

Figure 2 Forest plot showing prevalence of under-5 mortality in sub-Saharan Africa by country.

with married mothers (58.46\%); mothers whose pregnancies were unwanted $(62.84 \%)$, compared with those whose pregnancies were intended $(57.70 \%)$; and mothers with no formal education $(65.11 \%)$, compared with those with secondary/higher education (44.37\%). Mother's with normal body weight had higher prevalence of adolescent childbirth $(61.45 \%)$, compared with those whose body weight was obese $(51.09 \%)$. Adolescent childbirth was higher among mothers whose children were $\geq 2500 \mathrm{~g}$ (59.05\%), compared with those whose children were $<2500 \mathrm{~g}(54.69 \%)$. Higher prevalence of adolescent childbirth was observed among mothers who had less than four ANC visits $(63.83 \%)$, those who delivered at home $(68.54 \%)$, and those who were assisted by TBA/others during delivery $(67.62 \%)$, compared with those who had four or more ANC visits (54.75\%), those who delivered at the health facility (54.09), and those whose deliveries were assisted by SBA/health professional (55.40\%), respectively. Adolescent childbirth was higher among poorest mothers $(65.45 \%)$, compared with richest mothers $(42.81 \%)$ and mothers who lived in rural areas $(62.92 \%)$ compared with those who lived in urban areas $(50.20 \%)$. Mothers who lived in Central Africa had the highest prevalence of adolescent childbirth in terms of subregion $(65.64 \%)$.

With under-5 mortality, children born to single mothers had a higher prevalence of under-5 mortality $(5.07 \%)$, compared with those who were cohabiting (3.99\%). Children of mothers whose pregnancies were intended had a higher prevalence of under-5 mortality (4.47\%), compared with those whose pregnancies were mistimed $(3.50 \%)$. The highest prevalence of under-5 mortality was found among children of mothers who lived in rural areas $(4.46 \%)$, those with no formal education $(5.09 \%)$ 


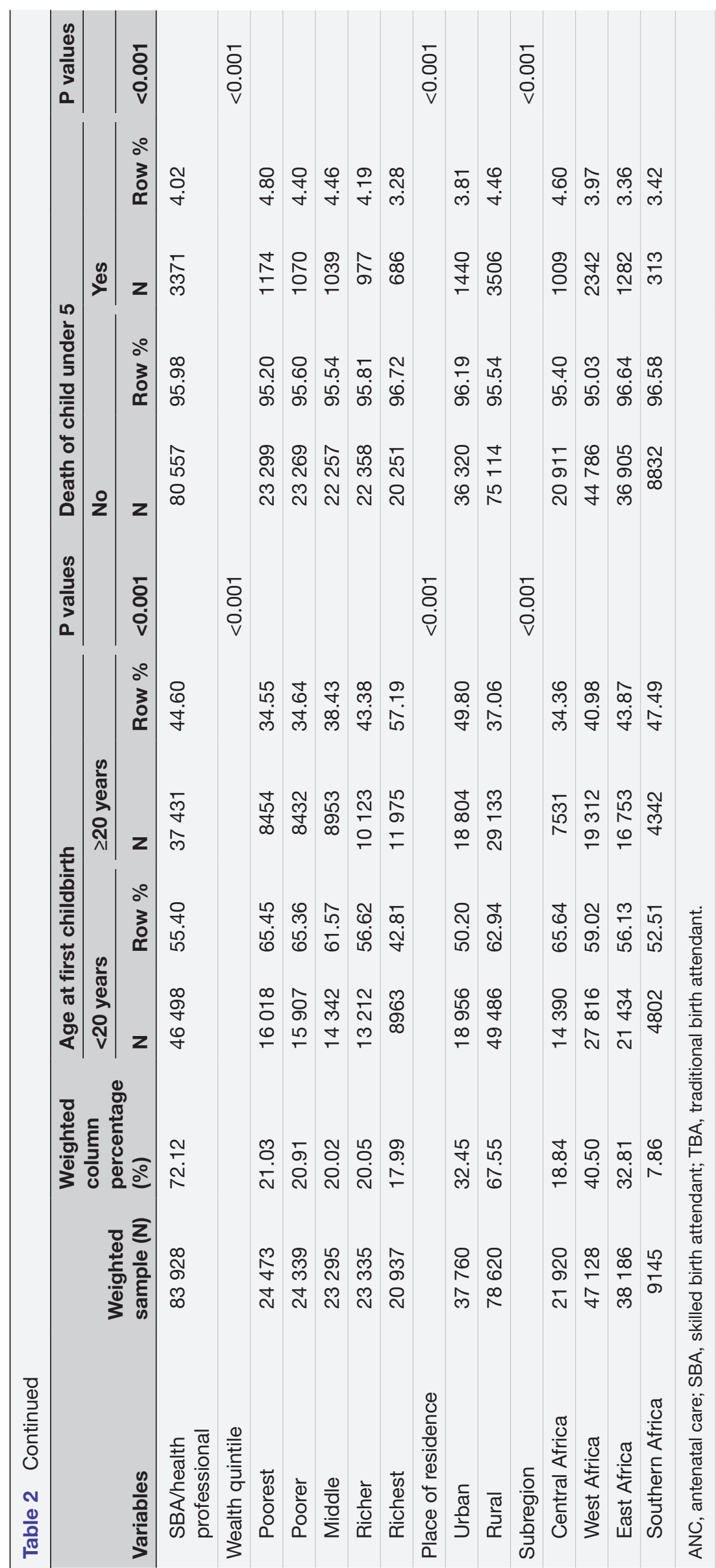


and those of the poorest wealth quintile $(4.80 \%)$. The highest deaths of under-5 children were also observed among male children $(4.57 \%)$, children whose weight was $<2500 \mathrm{~g}(6.63 \%)$, children whose mothers had less than four ANC visits (4.93\%), those who were delivered at home $(4.93 \%)$ and mothers who were assisted by TBA/ Others during delivery (4.85\%). Finally, under-5 mortality was highest in West Africa (3.97\%) in terms of subregion.

\section{Association between adolescent childbirth and under-5 mortality}

Model III of table 3 shows the results of the association between age at first childbirth under-5 mortality, while controlling for all the covariates. The results indicate that children born to mothers whose first childbirth occurred at $<20$ years were $11 \%$ more likely to die before the age of 5 compared with those whose mothers' first childbirth occurred at age $\geq 20$ years (aOR $1.11 ; 95 \%$ CI 1.05 to 1.18 ).

In terms of the covariates, the likelihood of under- 5 mortality was higher among single (aOR 1.54; 95\% CI 1.41 to 1.67 ) and cohabiting mothers (aOR 1.10; $95 \%$ CI 1.01 to 1.21) compared with married mothers. Children born to mothers who were obese were more likely to die before the age of 5 compared with those born to mothers with normal body weight (aOR 1.17; 95\% CI 1.09 to 1.26). The odds of under-5 mortality were higher among children whose weight at birth was $<2500 \mathrm{~g}$ compared with those whose weight was $\geq 2500 \mathrm{~g}$ at birth (aOR 1.83; 95\% CI 1.64 to 2.03$)$. On the contrary, the likelihood of under-5 mortality was lower among children born to mothers with secondary/higher education, female children, children whose mothers had four or more ANC visits and delivered at the health facility, children born to richest women, and children whose mothers lived in East and Southern Africa (see model III of table 3).

\section{DISCUSSION}

The aim of this study was to examine the association between adolescent childbirth and under-5 mortality in SSA. It was revealed that children born to mothers whose first childbirth occurred at $<20$ years were more likely to die compared with those born to mothers whose first childbirth occurred at age $\geq 20$ years. In terms of the higher odds of under- 5 mortality among adolescent mothers, the finding is consistent with the findings of previous studies in sub-Saharan African countries like Nigeria ${ }^{38}$ and South Sudan. ${ }^{39}$ Apart from these country-specific studies, other studies in low-income and middle-income countries, including SSA and others outside the subregion, have also found that young maternal age at first birth increases the risk of death of children under $5 .{ }^{262746}$ Several physiological, sociocultural, and socioeconomic factors may account for the higher odds of under-5 mortality among children born to adolescent mothers compared with those born to mothers aged 20 years and above. Physiologically, the younger the body of the mother the higher the likelihood of pregnancy and childbirth complications, which increase the risk of under-5 mortality. ${ }^{47}{ }^{48}$ Socioculturally, adolescent mothers are more likely to be stigmatised and face barriers accessing maternal and child healthcare services, predisposing children born to them to mortality. ${ }^{21-24}$ Socioeconomically, compared with adult mothers, adolescent mothers are more likely to have low level of education and low wealth status, which have been considered as predictors of under-5 mortality. ${ }^{9} 17424950$ Considering that some of the women whose first childbirth occurred when they were adolescents may not be adolescents at the time of the survey, the results on the association between adolescent childbearing and under-5 mortality provides an indication that the negative effects of adolescent childbearing on under- 5 mortality may extend over several years. Therefore, it is useful to mention that the problem is even more profound than we imagine and is not only short term or medium term but long term as well.

In this study, the likelihood of under-5 mortality was higher among single and cohabiting mothers compared with married mothers. Similar findings have been obtained in studies that have been conducted in SSA ${ }^{65152}$ and other low-income countries. ${ }^{53}{ }^{54}$ Most of these studies have cited lack of spousal support as the major reason for the high prevalence of under-5 mortality among children born to single and cohabiting women. ${ }^{65152}$ Other studies have also attributed the higher likelihood of under-5 mortality among children born to single and cohabiting mothers compared with married mothers to poor nutritional status, which manifest in stunting, wasting, and underweight and threaten the survival of children. ${ }^{556}$

Children born to mothers who were obese were more likely to die before the age of 5 compared with those born to mothers with normal body weight. Consistent with the findings of the current study, excessive maternal BMI has been found to be associated with high risk of under-5 mortality in previous studies ${ }^{57} 58$ Associations between maternal obesity and under-5 mortality could be attributed to pregnancy complications which are more common among obese mothers. For instance, obese mothers are more likely to deliver through caesarean section due to increased risks of obesity-related pregnancy complications and are also at higher risk of spontaneous extremely preterm delivery $(<28$ weeks $) .^{59} 60$ Relatedly, preterm infants are often affected by serious neonatal morbidities, which can threaten their survival. ${ }^{61}{ }^{62}$ Consistent with the findings of previous studies, ${ }^{763-65}$ it was found in this study that the odds of under-5 mortality were higher among children whose weight at birth was $<2500 \mathrm{~g}$ compared with those whose weight was $\geq 2500 \mathrm{~g}$ at birth. Studies have shown that the higher odds of mortality among children with low birth weight compared with those with normal body weight is attributed to poor health and disability often common among children with low birth weight. ${ }^{66-68}$

\section{Strengths and weaknesses}

The use of large nationally representative datasets of 30 countries in SSA in examining the association between 
Table 3 Multilevel logistic regression analysis on the association between adolescent childbirth and under-5 mortality

\begin{tabular}{|c|c|c|c|c|}
\hline Variables & Model 0 & $\begin{array}{l}\text { Model I cOR } \\
(95 \% \mathrm{Cl})\end{array}$ & $\begin{array}{l}\text { Model II aOR } \\
(95 \% \mathrm{Cl})\end{array}$ & $\begin{array}{l}\text { Model III aOR } \\
(95 \% \mathrm{Cl})\end{array}$ \\
\hline \multicolumn{5}{|l|}{ Fixed effects } \\
\hline \multicolumn{5}{|l|}{ Age at first childbirth } \\
\hline$<20$ years & & 1.21 (1.14 to 1.28$)$ & 1.15 (1.07 to 1.22$)$ & 1.11 (1.05 to 1.18$)$ \\
\hline$\geq 20$ years & & Ref & Ref & Ref \\
\hline \multicolumn{5}{|l|}{ Marital status } \\
\hline Married & & & Ref & Ref \\
\hline Cohabiting & & & 1.06 (0.97 to 1.16$)$ & 1.10 (1.01 to 1.21$)$ \\
\hline Single & & & 1.50 (1.38 to 1.63$)$ & 1.54 (1.41 to 1.67$)$ \\
\hline \multicolumn{5}{|l|}{ Pregnancy intention } \\
\hline Intended & & & Ref & Ref \\
\hline Mistimed & & & 0.79 (0.74 to 0.86$)$ & 0.84 (0.77 to 0.91$)$ \\
\hline Unwanted & & & 0.91 (0.81 to 1.03$)$ & 1.00 (0.88 to 1.12$)$ \\
\hline \multicolumn{5}{|l|}{ Mother's education level } \\
\hline No education & & & Ref & Ref \\
\hline Primary & & & 0.82 (0.76 to 0.88$)$ & 0.95 (0.88 to 1.02$)$ \\
\hline Secondary/higher & & & 0.71 (0.65 to 0.77$)$ & 0.78 (0.71 to 0.86$)$ \\
\hline \multicolumn{5}{|l|}{ Mother's body mass index } \\
\hline Normal & & & Ref & Ref \\
\hline Thin & & & 0.92 (0.84 to 1.02$)$ & 0.95 (0.86 to 1.05 ) \\
\hline Obese & & & 1.12 (1.05 to 1.21$)$ & 1.17 (1.09 to 1.26$)$ \\
\hline \multicolumn{5}{|l|}{ Sex of child } \\
\hline Male & & & Ref & Ref \\
\hline Female & & & 0.83 (0.79 to 0.88$)$ & 0.83 (0.78 to 0.88$)$ \\
\hline \multicolumn{5}{|l|}{ Child's weight } \\
\hline$\geq 2500 \mathrm{~g}$ & & & Ref & Ref \\
\hline$<2500 \mathrm{~g}$ & & & 1.78 (1.60 to 1.98$)$ & 1.83 (1.64 to 2.03 ) \\
\hline \multicolumn{5}{|l|}{ No of ANC visits } \\
\hline Less than four visits & & & Ref & Ref \\
\hline Four or more visits & & & 0.85 (0.80 to 0.90$)$ & 0.83 (0.78 to 0.88$)$ \\
\hline \multicolumn{5}{|l|}{ Place of delivery } \\
\hline Home & & & Ref & Ref \\
\hline Health facility & & & 0.76 (0.70 to 0.83$)$ & 0.82 (0.75 to 0.90$)$ \\
\hline \multicolumn{5}{|l|}{ Assistant during delivery } \\
\hline TBA/others & & & Ref & Ref \\
\hline SBA/health professional & & & 1.11 (1.02 to 1.21$)$ & 1.01 (0.93 to 1.10$)$ \\
\hline \multicolumn{5}{|l|}{ Wealth quintile } \\
\hline Poorest & & & & Ref \\
\hline Poorer & & & & 0.97 (0.89 to 1.06$)$ \\
\hline Middle & & & & 1.03 (0.94 to 1.12$)$ \\
\hline Richer & & & & 0.97 (0.88 to 1.07$)$ \\
\hline Richest & & & & 0.81 (0.72 to 0.92$)$ \\
\hline \multicolumn{5}{|l|}{ Place of residence } \\
\hline Urban & & & & Ref \\
\hline Rural & & & & 1.01 (0.93 to 1.10$)$ \\
\hline
\end{tabular}


Table 3 Continued

\begin{tabular}{|c|c|c|c|c|}
\hline Variables & Model 0 & $\begin{array}{l}\text { Model I cOR } \\
(95 \% \mathrm{Cl})\end{array}$ & $\begin{array}{l}\text { Model II aOR } \\
(95 \% \mathrm{Cl})\end{array}$ & $\begin{array}{l}\text { Model III aOR } \\
(95 \% \mathrm{CI})\end{array}$ \\
\hline \multicolumn{5}{|l|}{ Sub-region } \\
\hline Central Africa & & & & Ref \\
\hline West Africa & & & & 1.05 (0.94 to 1.16$)$ \\
\hline East Africa & & & & $0.62(0.55$ to 0.71$)$ \\
\hline Southern Africa & & & & 0.81 (0.69 to 0.93$)$ \\
\hline \multicolumn{5}{|l|}{ Year of survey } \\
\hline 2010 & & & & Ref \\
\hline 2011 & & & & 0.84 (0.66 to 1.05$)$ \\
\hline 2012 & & & & 0.89 (0.75 to 1.06$)$ \\
\hline 2013 & & & & 0.85 (0.70 to 1.03$)$ \\
\hline 2014 & & & & 1.02 (0.85 to 1.22$)$ \\
\hline 2015 & & & & $1.10(0.90$ to 1.34$)$ \\
\hline 2016 & & & & 1.26 (1.02 to 1.56$)$ \\
\hline 2017 & & & & 1.56 (1.21 to 2.02$)$ \\
\hline 2018 & & & & 1.21 (1.04 to 1.42$)$ \\
\hline 2019 & & & & 1.71 (1.40 to 2.08$)$ \\
\hline \multicolumn{5}{|l|}{ Random effects } \\
\hline PSU variance (95\% CI) & 0.02 (0.01 to 0.05$)$ & 0.02 (0.01 to 0.05$)$ & 0.02 (0.01 to 0.05$)$ & 0.02 (0.01 to 0.05$)$ \\
\hline ICC & 0.006 & 0.006 & 0.006 & 0.005 \\
\hline LR test & $\chi^{2}=5.67, p=0.009$ & $\chi^{2}=5.48, p=0.010$ & $\chi^{2}=5.19, p<0.011$ & $\chi^{2}=4.91, p=0.013$ \\
\hline Wald $\chi^{2}$ & Reference & $38.90, p<0.011$ & $471.05, p<0.011$ & $717.97, p<0.011$ \\
\hline \multicolumn{5}{|l|}{ Model fitness } \\
\hline Log-likelihood & -20207.49 & -20187.76 & -19972.82 & -19842.40 \\
\hline $\mathrm{AIC}$ & 40418.99 & 40381.52 & 39977.63 & 39750.80 \\
\hline Sample size & 116379 & 116379 & 116379 & 116379 \\
\hline
\end{tabular}

1=Reference category.

Source: Demographic and Health Surveys.

AIC, Akaike's information criterion; aOR, adjusted OR; cOR, crude OR; ICC, intraclass correlation; LR, likelihood ratio; PSU, primary sampling unit; SBA, skilled birth attendant; TBA, traditional birth attendant.

adolescent childbirth and under-5 mortality is a major strength of this study. Again, the large sample size made it possible to use high level statistical analyses that confirm the accuracy of the findings. Despite these strengths, there are some limitations inherent in this study. First, the design employed in the DHS is cross-sectional and hence, causal interpretations of the findings cannot be established. Second, age at first childbirth was self -reported, and as a result, there is the possibility of under-reporting and over-reporting of data. ${ }^{69-71}$ Since reporting under-5 mortality may bring about unpleasant moments, some mothers may under-report its occurrence. Finally, considering that some of the respondents in this study whose first birth occurred when they were adolescents were not adolescents at the time of the survey, under- 5 mortality reported by those people could be due to other factors and not necessarily because their first childbirth occurred when they were adolescents.

\section{CONCLUSION}

This study has established an association between adolescent childbirth and death of children under 5 in SSA. The findings have significant policy and public health implications. From the policy perspective, the findings call for the need to enhance policies aimed at reducing under-5 mortality in SSA by reducing adolescent pregnancy and childbirth through family planning, comprehensive sexuality education, and the elimination of child marriage. Again, there is the need for government and non-governmental organisations in SSA to introduce poverty alleviation programmes and improve access to both formal and informal education as a way of enhancing the socioeconomic status of adolescent mothers. Public health education should also be enhanced through continuous advocacy programmes as a way of helping adolescent mothers to access ANC and health facility deliveries. These interventions should be implemented, 
taking into consideration other characteristics of mothers such marital status and BMI and child's characteristics such as child's weight, which were found to be associated with high under-5 mortality.

Contributors BOA contributed to the study design and conceptualisation. BOA reviewed the literature performed the analysis and drafted the first draft of this manuscript. BOA provided technical support and critically reviewed the manuscript for its intellectual content. BOA had final responsibility to submit for publication. The author read and amended drafts of the paper and approved the final version.

Funding The authors have not declared a specific grant for this research from any funding agency in the public, commercial or not-for-profit sectors.

Competing interests None declared.

Patient consent for publication Not applicable.

Provenance and peer review Not commissioned; externally peer reviewed.

Data availability statement Data are available in a public, open access repository. Data for this study were sourced from Demographic and Health surveys (DHS) and available here: http://dhsprogram.com/data/available-datasets.cfm.

Supplemental material This content has been supplied by the author(s). It has not been vetted by BMJ Publishing Group Limited (BMJ) and may not have been peer-reviewed. Any opinions or recommendations discussed are solely those of the author(s) and are not endorsed by BMJ. BMJ disclaims all liability and responsibility arising from any reliance placed on the content. Where the content includes any translated material, BMJ does not warrant the accuracy and reliability of the translations (including but not limited to local regulations, clinical guidelines, terminology, drug names and drug dosages), and is not responsible for any error and/or omissions arising from translation and adaptation or otherwise.

Open access This is an open access article distributed in accordance with the Creative Commons Attribution Non Commercial (CC BY-NC 4.0) license, which permits others to distribute, remix, adapt, build upon this work non-commercially, and license their derivative works on different terms, provided the original work is properly cited, appropriate credit is given, any changes made indicated, and the use is non-commercial. See: http://creativecommons.org/licenses/by-nc/4.0/.

ORCID iD

Bright Opoku Ahinkorah http://orcid.org/0000-0001-7415-895X

\section{REFERENCES}

1 Adebowale AS, Fagbamigbe AF, Morakinyo O, et al. Parental educational homogamy and under-five mortality in sub-Saharan Africa: Clarifying the association's intricacy. Sci Afr 2020;7:e00255.

2 UNICEF. Levels \& trends in child mortality: estimates developed by the UN inter-agency group for child mortality estimation. New York: Estimation UIGfCM, 2019.

3 Chao F, You D, Pedersen J, et al. National and regional under-5 mortality rate by economic status for low-income and middleincome countries: a systematic assessment. Lancet Glob Health 2018:6:e535-47.

4 Cha S, Jin Y. Have inequalities in all-cause and cause-specific child mortality between countries declined across the world? Int J Equity Health 2020;19:1-13.

5 Roser M, Ritchie H, Dadonaite B. Child \& Infant Mortality. Our World in Data, 2013.

6 Yaya S, Bishwajit G, Okonofua F, et al. Under five mortality patterns and associated maternal risk factors in sub-Saharan Africa: a multicountry analysis. PLoS One 2018;13:e0205977.

7 Yaya S, Uthman OA, Okonofua F, et al. Decomposing the rural-urban gap in the factors of under-five mortality in sub-Saharan Africa? Evidence from 35 countries. BMC Public Health 2019;19:616.

8 Acheampong M, Ejiofor C, Salinas-Miranda A, et al. Priority setting towards achieving under-five mortality target in Africa in context of sustainable development goals: an ordinary least squares (OLS) analysis. Glob Health Res Policy 2019;4:3.

9 Ahinkorah BO, Seidu A-A, Budu E, et al. Proximate, intermediate, and distal predictors of under-five mortality in Chad: analysis of the 2014-15 Chad demographic and health survey data. BMC Public Health 2020;20:1-12.

10 United Nations. Sustainable development goals. New York: United Nations, 2015

11 WHO. Causes of child mortality, 2017.
12 Kyei-Nimakoh M, Carolan-Olah M, McCann TV. Access barriers to obstetric care at health facilities in sub-Saharan Africa-a systematic review. Syst Rev 2017;6:110.

13 Wong KLM, Benova L, Campbell OMR. A look back on how far to walk: systematic review and meta-analysis of physical access to skilled care for childbirth in sub-Saharan Africa. PLoS One 2017;12:e0184432.

14 Geleto A, Chojenta C, Musa A, et al. Barriers to access and utilization of emergency obstetric care at health facilities in sub-Saharan Africa: a systematic review of literature. Syst Rev 2018;7:183.

15 Brown J, Cairncross S, Ensink JHJ. Water, sanitation, hygiene and enteric infections in children. Arch Dis Child 2013;98:629-34.

16 Liu L, Hill K, Oza S. Levels and causes of mortality under age five years. In: Reproductive, maternal, newborn, and child health, 2016: 71.

17 Yaya S, Ahinkorah BO, Ameyaw EK, et al. Proximate and socioeconomic determinants of under-five mortality in Benin, 2017/2018. BMJ Glob Health 2020;5:e002761.

18 Bado AR, Appunni SS. Decomposing wealth-based inequalities in under-five mortality in West Africa. Iran J Public Health 2015;44:920.

19 Neal S, Channon AA, Chintsanya J. The impact of young maternal age at birth on neonatal mortality: evidence from 45 low and middle income countries. PLoS One 2018;13:e0195731.

20 Grønvik T, Fossgard Sandøy I, Sandøy F I. Complications associated with adolescent childbearing in sub-Saharan Africa: a systematic literature review and meta-analysis. PLoS One 2018;13:e0204327.

21 Rani M, Lule E. Exploring the socioeconomic dimension of adolescent reproductive health: a multicountry analysis. Int Fam Plan Perspect 2004:30:110-7.

22 Chirwa GC, Mazalale J, Likupe G, et al. An evolution of socioeconomic related inequality in teenage pregnancy and childbearing in Malawi. PLoS One 2019;14:e0225374.

23 Reynolds HW, Wong EL, Tucker H. Adolescents' use of maternal and child health services in developing countries. Int Fam Plan Perspect 2006;32:6-16.

24 Atuyambe L, Mirembe F, Tumwesigye NM, et al. Adolescent and adult first time mothers' health seeking practices during pregnancy and early motherhood in Wakiso district, central Uganda. Reprod Health 2008;5:13.

25 Mahy M. Childhood mortality in the developing world: a review of evidence from the demographic and health surveys: measure DHS+, ORC macro 2003.

26 Finlay JE, Özaltin E, Canning D. The association of maternal age with infant mortality, child anthropometric failure, diarrhoea and anaemia for first births: evidence from 55 low- and middle-income countries. BMJ Open 2011;1:e000226.

27 Sinha S, Aggarwal AR, Osmond C, et al. Maternal age at childbirth and perinatal and under five mortality in a prospective birth cohort from Delhi. Indian Pediatr 2016;53:871-7.

28 Kim Y-N, Choi D-W, Kim DS, et al. Maternal age and risk of early neonatal mortality: a national cohort study. Sci Rep 2021;11:814

29 Restrepo-Méndez MC, Victora CG. Maternal mortality by age: who is most at risk? Lancet Glob Health 2014;2:e120-1.

30 Psaki SR, Soler-Hampejsek E, Saha J, et al. The effects of adolescent childbearing on literacy and Numeracy in Bangladesh, Malawi, and Zambia. Demography 2019:56:1899-929.

31 Assini-Meytin LC, Green KM. Long-Term consequences of adolescent parenthood among African-American urban youth: a propensity score matching approach. $J$ Adolesc Health 2015;56:529-35.

32 Grant MJ, Hallman KK. Pregnancy-Related school dropout and prior school performance in KwaZulu-Natal, South Africa. Stud Fam Plann 2008;39:369-82.

33 Osok J, Kigamwa P, Stoep AV, et al. Depression and its psychosocial risk factors in pregnant Kenyan adolescents: a cross-sectional study in a community health centre of Nairobi. BMC Psychiatry 2018:18:136.

34 Govender D, Naidoo S, Taylor M. Antenatal and postpartum depression: prevalence and associated risk factors among adolescents' in KwaZulu-Natal, South Africa. Depress Res Treat 2020;2020:5364521.

35 Ayamolowo SJ, Olajubu AO, Akintola FE. Perceived social support and depression among pregnant and child-rearing teenagers in lleIfe, Southwest Nigeria. Afr J Midwifery Womens Health 2019;13:1-9.

36 Ahinkorah BO, Kang M, Perry L, et al. Prevalence of first adolescent pregnancy and its associated factors in sub-Saharan Africa: a multicountry analysis. PLoS One 2021;16:e0246308.

37 Neal S, Channon AA, Chandra-Mouli V, et al. Trends in adolescent first births in sub-Saharan Africa: a tale of increasing inequity? Int $J$ Equity Health 2020;19:1-11. 
38 Ayotunde T, Mary O, Melvin AO, et al. Maternal age at birth and under-5 mortality in Nigeria. East Afr J Public Health 2009;6:11-14.

39 Mugo NS, Agho KE, Zwi AB, et al. Determinants of neonatal, infant and under-five mortality in a war-affected country: analysis of the 2010 household health survey in South Sudan. BMJ Glob Health 2018;3:e000510.

40 Corsi DJ, Neuman M, Finlay JE, et al. Demographic and health surveys: a profile. Int J Epidemiol 2012;41:1602-13.

41 von Elm E, Altman DG, Egger M, et al. The strengthening the reporting of observational studies in epidemiology (STROBE) statement: guidelines for reporting observational studies. Int J Surg 2014;12:1495-9.

42 Van Malderen C, Amouzou A, Barros AJD, et al. Socioeconomic factors contributing to under-five mortality in sub-Saharan Africa: a decomposition analysis. BMC Public Health 2019;19:760.

43 Sisay W, Tesema GA, Worku MG. Trend and factors associated with under-five mortality in Ethiopia further analysis of 20002016 Ethiopian demographic and health survey: a multivariate decomposition analysis, 2020.

44 United Nations. Standard Country or Area Codes for Statistics Use, 1999 (Revision 4), 1999. Available: https://unstats.un.org/unsd/ publications/catalogue?selectID=109 [Accessed 23 May 2020].

45 ICF International. Demographic and health survey sampling and household listing manual. MEASURE DHS, Calverton, Maryland, U.S.A: ICF International, 2012.

46 Gibbs CM, Wendt A, Peters S, et al. The impact of early age at first childbirth on maternal and infant health. Paediatr Perinat Epidemiol 2012;26 Suppl 1:259-84.

47 WHO. Maternal mortality, 2019.

48 Cavazos-Rehg PA, Krauss MJ, Spitznagel EL, et al. Maternal age and risk of labor and delivery complications. Matern Child Health $J$ 2015;19:1202-11.

49 Nattey C, Masanja H, Klipstein-Grobusch K. Relationship between household socio-economic status and under-five mortality in Rufiji DSS, Tanzania. Glob Health Action 2013;6:19278.

50 Chowdhury AH, Hanifi SMA, Mia MN, et al. Socioeconomic inequalities in under-five mortality in rural Bangladesh: evidence from seven national surveys spreading over 20 years. Int J Equity Health 2017:16:197.

51 Ekholuenetale M, Wegbom Al, Tudeme G, et al. Household factors associated with infant and under-five mortality in sub-Saharan Africa countries. International Journal of Child Care and Education Policy 2020;14:10

52 Van Malderen C, Amouzou A, Barros AJD, et al. Socioeconomic factors contributing to under-five mortality in sub-Saharan Africa: a decomposition analysis. BMC Public Health 2019;19:1-19.

53 Dendup T, Zhao Y, Dema D. Factors associated with under-five mortality in Bhutan: an analysis of the Bhutan National health survey 2012. BMC Public Health 2018:18:1-15.

54 Mugo NS, Mya KS, Raynes-Greenow C. Exploring causal pathways for factors associated with neonatal, infant and under-five mortality, analysis of 2015-2016 Myanmar demographic health survey. J Glob Health Rep 2019;3:e2019015.
55 Ntoimo LFC, Odimegwu CO. Health effects of single motherhood on children in sub-Saharan Africa: a cross-sectional study. BMC Public Health 2014;14:1-13.

56 Amadu I, Seidu A-A, Duku E, et al. The joint effect of maternal marita status and type of household cooking fuel on child nutritional status in sub-Saharan Africa: analysis of cross-sectional surveys on children from 31 countries. Nutrients 2021:13:1541.

57 Johansson S, Villamor E, Altman M, et al. Maternal overweight and obesity in early pregnancy and risk of infant mortality: a population based cohort study in Sweden. BMJ 2014;349:96572.

58 Cresswell JA, Campbell OMR, De Silva MJ, et al. Effect of maternal obesity on neonatal death in sub-Saharan Africa: multivariable analysis of 27 national datasets. Lancet 2012;380:1325-30.

59 Guelinckx I, Devlieger R, Beckers K, et al. Maternal obesity: pregnancy complications, gestational weight gain and nutrition. Obes Rev 2008;9:140-50.

60 Villamor E, Cnattingius S. Interpregnancy weight change and risk of adverse pregnancy outcomes: a population-based study. Lancet 2006;368:1164-70.

61 Ambalavanan N, Carlo WA, Tyson JE, et al. Outcome trajectories in extremely preterm infants. Pediatrics 2012;130:e115-25.

62 Soll RF. Early versus delayed selective surfactant treatment for neonatal respiratory distress syndrome. Neonatology 2013;104:124-6.

63 Budu E, Ahinkorah BO, Ameyaw EK, et al. Does birth interval matter in Under-Five mortality? Evidence from demographic and health surveys from eight countries in West Africa. Biomed Res Int 2021;2021:1-10.

64 Vilanova CS, Hirakata VN, de Souza Buriol VC, et al. The relationship between the different low birth weight strata of newborns with infant mortality and the influence of the main health determinants in the extreme South of Brazil. Popul Health Metr 2019;17:1-12.

65 Mayor S. Low birth weight is associated with increased deaths in infancy and adolescence, shows study. BMJ 2016;353:i2682.

66 Goldenberg RL, Culhane JF. Low birth weight in the United States. Am J Clin Nutr 2007;85:584S-90.

67 Horbar JD, Badger GJ, Carpenter JH, et al. Trends in mortality and morbidity for very low birth weight infants, 1991-1999. Pediatrics 2002;110:143-51.

68 Kusuda S, Fujimura M, Sakuma I, et al. Morbidity and mortality of infants with very low birth weight in Japan: center variation. Pediatrics 2006;118:e1130-8.

69 Ahinkorah BO. Individual and contextual factors associated with mistimed and unwanted pregnancies among adolescent girls and young women in selected high fertility countries in subSaharan Africa: a multilevel mixed effects analysis. PLoS One 2020;15:e0241050

70 Ahinkorah BO. Predictors of unmet need for contraception among adolescent girls and young women in selected high fertility countries in sub-Saharan Africa: a multilevel mixed effects analysis. PLoS One 2020;15:e0236352.

71 Ahinkorah BO. Predictors of modern contraceptive use among adolescent girls and young women in sub-Saharan Africa: a mixed effects multilevel analysis of data from 29 demographic and health surveys. Contracept Reprod Med 2020;5:32. 